\title{
THE CHANGING ROLE OF PESTICIDES IN PEST MANAGEMENT
}

\author{
G. A. SCHAEFERS \\ Cornell University, Geneva, N.Y. 14456, USA
}

\begin{abstract}
Significant changes have occurred in the role of pesticides in pest management programmes since the publication of Carson's book Silent Spring in 1962. This discourse addresses the multitude of factors which contributed to these changes including such factors as policy and legislation, the public's perception of associated risks, population pressures, the availability of practical integrated pest management programmes, and perhaps most importantly, the constraints to IPM in Third World countries. While reliable statistics are difficult to obtain, the changing patterns in pesticide use in the tropical regions are also discussed. Finally, the future of pesticide use in developing countries is projected, as is the necessity of their use and expected impacts.
\end{abstract}

Key Words: policy, legislation, environmental impact, production, cultural control

\begin{abstract}
Résumé-Des changements significatifs ont eu lieu à propos du rôle des pesticides dans des programmes de lutte dirigée depuis la parution du livre de Carson "Le printemps silencieux" en 1962. Cet exposé aborde la multitude des facteurs qui ont contribué à ces changements, notament des facteurs tels que politique et législation, perception des risques associés par le public, pressions démographiques, disponibilité des programmes pratiques de lutte dírigée èt plus important peut être, les contraintes à la lutte dirigée dans le Tiers-Monde. Alors que des statistiques fiables sont difficiles à obtenir, les modes de changement dans l'usage des pesticides dans les régions tropicales sont aussi discutés. Finalement, des projections concernant l'avenir de l'usage des pesticides dans les pays en voie de développement sont faites tout comme sur la nécessité de leur usage et de leurs impacts attendus.
\end{abstract}

Mots Clés: politique, législation, impact écologique, production, lutte au moyen de practiques culturales

\section{INTRODUCTION}

The use of chemical pesticides remains one of the best known and most widely used pest control tactics. When properly used they provide an efficient, fast, neliable, and cost-effective means of pest control. The drawbacks or risks in their use are also well known, however. Those most often cited include development of resistance, destruction of natural enemies, poisoning of man and animals, environmental pollution, and increasing costs.

Since the objective of this paper is to discuss the changing roles of pesticides in pest management, it is appropriate to discuss what we mean by the individual terms, and how they themselves have changed. First, the generic term "pesticide"does notexist in Webster's New World Dictionary, although more specific terms including "insecticide" are listed. The more euphemistic agricultural term of "crop protectants" is increasingly used and might be more appropriate for several reasons. First, it avoids the alarmist connotations of ". . . . cide" as killing, poison, and death, for example. Second, the goal of integrated pest management (IPM) is not necessarily to kill pests, but to reduce crop damage, and escape from insect-transmitted diseases, an accomplishable goal with the use of modern 4th generation protectants which act as behavioural modifiers including antifeedents, repellents, and mating interrupters.

Further, distinction should be made between pest management, which is a goal, and integrated pest management, which is an enlightened approach to this goal. This distinction is all too often obscured. Finally, while "management" has useful but subtle meanings in English, it is not always the case in other languages, hence the recommendation to use the 
term integrated pest "control", which has a more international meaning.

The changing role of pesticides in pest management may be viewed from three historical levels, i.e., treat according to the calendar or when the pest is observed, treat when the relationship between pest density and yield loss is warranted, and treat when all alternative (biointensive) tactics become ineffective. Clearly, in the first instance, the approach accounted for large amounts of pesticides being used unnecessarily. The next level, which invoked the use of "economic or pest density thresholds" was a significant improvement in pesticide management in that it provided for treatment on an "as-needed" basis. For many years, however, IPM in this mode represented little more than modified spray programmes involving the intelligent use of pesticides.

The widely accepted definition of IPM (Smith and Reynolds, 1966) specifies the utilisàtion of "all suitable techniques" including pesticides. While the arguments against the use of pesticides have been largely emotive and exaggerated, they do contain a core of truth (Haskell, 1977) and certainly in past years there has been an overreliance on the use of pesticides in IPM programmes. In many IPM programmes there is a reduction in the amount of pesticides used, but in others there may well be an increase in use, but never more than is necessary: Current thought removes pesticides as a cornerstone tactic and shifts emphasis to more biointensive tactics including biological control, host resistance, and cultural management (Frisbie and Smith, 1989). The FAO approach to integrated pest control is also based on proper cultural practices and the associated natural biological control elements (Brader, 1982). Once this simple model is in place, then various selective control means such as pest-resistant varieties, natural enemies, entomopathogens, and selective pesticide applications can be introduced. It is important to realise, however, that this shift away from the pesticide emphasis does not detract from the logic and appropriateness of a multiple, all-suitable-techniques strategy for sustainable pest management. Integrated pest management is, in fact, a long-term crop protection policy of sustainability.

In addition to the conceptual shift concerning the reduced emphasis on pesticides in the development of biointensive IPM, the selection and extent of pesticide use in pest management is strongly influenced by a host of multifarious factors. These factors, all of which cannot be covered here, exert often unseen or unrecognised, positive or negative pressures on the need for pesticides in agricultural and health situations, the selection and availability of specific compounds, and the extent to which they are used. Recognition of these factors is critical to an understanding of the changes in pesticide use in the tropics since the writing of Carson's (1962) Silent Spring.

\section{FACTORS CONTRIBUTING TO CHANGES IN PESTICIDE USE}

\section{Pesticide policy and legislation with international impacts}

A number of international actions have been undertaken that impact on pesticide use in developing countries. Such policies and legislation are aimed at improved pesticide management, a practice that can help avoid pesticide misuse and the possible loss of a valuable and badly needed pest control tactic in the third world.

Environmental procedures of the United States Agency for International Development (USAID) (22 CFR 216) "Reg. 16" require that the agency assess the impact of pesticides on public health and the environment before approving funding for their provision or use. However, since USAID missions are in-country by invitation, they lack authority to enforce beneficial procedures and reforms, although economic and food aid can have a significant influence on the acceptance of such reforms. Nevertheless, problems do result, since USAID's priorities do not always coincide with those for the country. For example, many countries still consider environmental management to be a.luxury (Anon, 1988), and the regulation is viewed by many as being too strict. Changes resulting from the implementation of this regulation include a reduction in amount of pesticides provided through USAID's projects, restrictions on their use to protect health and the environment, causing some countries or agencies to reconsider or revise their pesticide use policies, and initiating projects that address environmental concerns directly.

An attempt has been made to harmonise international pesticide residue standards through legislation that affects shipment of food items. Food and Agriculture Organisation/World Health Organisation established the Codex Alimentarius Commission in 1963. The Commission established acceptable Maximum Residue Limits for food coming into international trade. These are then offered to participating countries for acceptance. They are gradually accepting them, albeit slowly. This approach brings the power of quarantine into play and helps to avoid the "circle of poison" phenomenon which involves the shipping of unregistered pesticides to foreign countries which then return them in imported food. 
United States pesticide regulations represent the maximum in complexity, and the history of the USA pesticide legislation is long and varied, starting with the Federal Insecticide Act of 1910. This was succeeded by the Federal Insecticide, Fungicide, and Rodenticide Act (FIFRA) in 1947, the National Environmental Policy Act of 1969 which established the Environmental Protection Agency (EPA), and the reform of FIFRA, by the Federal Environmental Pesticides Control Act in 1972. Since then there has been a proliferation of legislation, increasing the stringency for registration as well as re-registration of pest control products. Each of these actions has had significant impacts worldwide on the availability, selection, and use of crop protectants. Actions such as these will create the economic incentives for farmers to use non-chemical pest control methods (NRC, 1989).

Certainly, the lowering of FDA tolerances for pesticide residues and insect parts have forced changes in the kinds and quantity of pesticides used.

An International Code of Conduct on the Distribution and Use of Pesticides was developed by the FAO Conference in its Twenty-Third session in 1985. It was amended to include prior consent in 1989. Basically, the Code, which is voluntary in nature, is meant to serve as a point of reference, particularly until such time as countries have established adequate regulatory infrastructures for pesticides on their own.

Clearly, the outright banning or cancellation of pesticide registrations, particularly those in use for many years, can have a significant, but hopefully beneficial, impact on pest management programmes. Action to phase out DDT registrations started in the late 1960 s based on undesirable persistence and danger to wildlife, but it was not until 1972 that essentially all uses were cancelled on the basis that it was a cancer hazard to man (Alford, 1985). Most uses of aldrin and dieldrin were cancelled in 1974 while most uses of chlordane and heptachlot were banned in 1978. As of this time, over 40 pesticides are included on the suspended, cancelled and restricted list by the United States of America Environmental Protection Agency (USEPA), and these do not include those restricted to use by certified applicators. While tropical countries will be most impacted by Federal programmes in the USA, they will also ultimately be affected by State programmes if those programmes influence the profitable marketability of a product.

In addition, there have been many volunteer cancellations as a result of an accelerated reregistration process. There exists some confusion in the mind of the public between the meaning of banned pesticides and those not registered. While cancellation of registration status may well result from toxicological or environmental problems, nonregistration may also be due to lack of market for the product, or to the fact that the particular crop for which the pesticide is intended is not grown in that country. Actually, many insecticides registered in other countries are not registered in the United States.

Most pesticides used in developing countries originated in developed countries. Some have been prohibited, severely restricted, or have never been registered for use in the developed countries, but under current laws it is perfectly legal for manufacturers in these countries to export these products to the developing countries (Bottrell, 1983). The USA exports 182-273 million $\mathrm{kg}$ of pesticides each year, most of which go to Asia and Latin America, with least going to Africa. However, it is not considered a major supplier of pesticides to the Third World, actually supplying only about $16.5 \%$ of the exports worldwide. The USA along with other countries has been accused of dumping pesticides (which have not met US quality control standards) on developing countries. One report (GAO, 1979) claims that $25 \%$ of the pesticide exports from the United States fall in the "dumping" category. They include highly toxic insecticides such as aldicarb, methyl parathion, carbofuran and persistent chlorohydrocarbons such as DDT (Bottrell, 1983). However, a number of materials manufactured especially for export can be legally shipped. It is now required of US exporters to inform foreign buyers of the known dangers of any materials shipped as well as any changes in the regulatory status of the chemical in the US (USAID, 1990). Further, Article 9 of the FAO Code of Conduct recommends a formal procedure, referred to as "prior informed consent", for notifying governments before the shipment of pesticides which are banned or restricted in the exporting countries.

\section{National programmes and legislation governing import and use of pesticides}

Some $10-15$ years behind the industrialised nations, several African countries have only recently banned DDT, aldrin, and other chlorinated hydrocarbons (Brosten and Simmonds, 1989). Most countries of the third world lack pesticide control statutes and those that do exist are not strongly or vigorously enforced. Legislation was adopted in Kenya when the Pest Control Products Act of 1982 was implemented in 1983 through a Board of Management. This board is responsible for the entire management of pesticides in Kenya including marketing and packaging, consistent with the FAO Code of Conduct (Kibata, 1992). Enforcement is not 
without constraints, however (Kibata, 1985). In 1985, 51 African nations adopted the FAOCode of Conduct on the Distribution and Use of Pesticides (Brosten and Simmonds, 1989). In Central America, most countries have a number of statutes or decrees which attempt toprevent problems associated with pesticides and while some are more comprehensive than others, none of the countries are equipped to adequately enforce the pesticide laws (Anon, 1988).

National programmes related to economic conditions often lead to government pricing and subsidies for pesticide inputs with the intent of stimulating production. Senegal, for example, subsidised pesticide use on rice in order to avoid loss of foreign exchange through the importation of rice. Such practices clearly lead to increased use as well as misuse of pesticides. For example, the per caput subsidies in Honduras, resulting from policies such as giving pesticide importers a favourable rate of exchange and exempting pesticides from sales taxation, were among the highest in a group of nine countries studied (Repetto, 1985). An average subsidy of total retail cost for the nine countries studied was $44 \%$. This encouraged more use, discouraged the use of alternatives, and undermined cost-effective methods such as economic thresholds. Often such programmes benefit the larger-scale farmers compared to the smaller-scale farmers, again mostly on cash crops (Repetto, 1985). Although the goals are different, similar consequences result from the subsidisation of vector control programmes. The introduction of Structural Adjustment Programmes in some West African countries has necessitated the removal of government subsidies on pesticides and replacement with new incentives of high producer prices. Because of the increased revenues, farmers are able to purchase pesticides at the current high selling prices. Despite the higher prices, pesticide consumption continues to rise (FAO, 1990).

Another governmental factor contributing to excessive use results when political pressures, driven by economic concerns, cause governments to give more funding and support to agricultural and commerce ministries than to environmental ministries (Anon, 1988). As discussed by Goodell (1984), control measures that require little extension, such as pesticides included in simplified technology packages, along with resistant varieties and biological control releases, remain under centralised governmental control. Policy makers generally prefer measures that they, rather than the farmer, can control. Goodell (1984) concluded that centrally controlled agriculture is less efficient than diversified and decentralised ecosystem management, a conclusion receiving little argument in recent years. The concept that the pesticide tactic requires less extension input; including the "simplified" package, has clearly been a pathway chosen in error. Pesticide management is obviously. not a simple approach but a highly complex decisionmaking strategy, which does, in fact, require high levels of extension if it is to be used appropriately in developing IPM programmes.

The public's perception of pesticide-associated environmental and public health risks

In spite of greatly intensified and restrictive requirements for registration of pesticides and a greatly accelerated programme for the re-registration of existing compounds as well as substantial scientific conclusions on pesticide safety, agricultural pesticides are still perceived as unacceptably hazardous to human health and the environment. These perceptions continue to encourage the development of additional pesticide regulation (Farrell, 1990). Clearly, the resulting decline in available pesticide choices will severely limit, not only chemical pest control options, but the flexibility they offer in terms of developing IPM programmes.

According to Tucker (1978) three fundamental problems have caused the current dilemma of environmentalism. First is the myth, which environmentalists have fashioned, of an ideal, prepesticide past, when crops had vigour, living was easy, and insects were few. This is a complete fantasy. Second, there is the false distinction between natural and unnatural chemicals and implicit assumptions that chemicals, such as pesticides, never occur in nature. Third, there is the myth that these unnatural chemicals are causing an equally mythical, epidemic increase in cancer. Unfortunately, the genesis of all three of these ideas can be traced directly to Carson's Silent Spring.

Integrated pest management itself is subject to credibility with farmers. Farmers often receive distorted views of IPM as "pest control without chemicals" or as "biological control" and as a result become reluctant to relinquish their pesticideoriented, but dependable, pest management programmes.

\section{Industrial production and pesticide development}

It is the older, less expensive, chemicals that are often used in developing countries. These materials are no longer patent-protected and do not provide adequate profit for multinational companies. The materials are then manufactured in the developing countries, often without compliance with safety requirements or the production standards of the larger 
companies. Profit becomes a driving force for pesticide manufacturers. For example, the public health market for pesticides is estimated at about US $\$ 1$ billion compared to $\$ 25$ billion for the agricultural market. The extra requirements for registration of newer compounds for public health use discourage development of new compounds for this relatively limited market.

The pesticide industry has redirected its efforts to "more IPM-compatible products",i.e., more selective chemicals with better target specificity. Benefits to industry will accrue from a sustainable IPM strategy (Vorley, 1992). Directed and selective use of pesticides results in better resistance management, longer product life, improved grower satisfaction, minimum operator contamination, support from public and policy makers, and also meets the FAO Code of Conduct commitments.

Such products are more expensive, so industry directs the marketing to areas where growers can afford them and they even advise on economic thresholds. Industry is reluctant to invest in remote situations because of small profit margins and the difficult logistics of influencing thousands of scattered small-scale farmers. However, given that small-scale farmers will be the main agents for future intensification, endorsement of non-sustainable practices in this sector is incompatible with good business practices (Vorley, 1992). Intensification and sustainability represent a contradiction in that intensification requires increased inputs. The contradiction holds true, particularly when the classic, or "pure" definition of sustainability refers to no offfarm inputs. It is evident that sustainability does not exist in this sense, since increased agricultural production cannot be accomplished without a price. Further, because pesticides are extension intensive, small-scale farmers are often not considered part of the game plan.

Delayed registration of crop protectants causes serious and often unnecessary modifieations of IPM programmes. The problems with the registration of Bacillus thuringiensis (B.t.) was related by Tucker (1978). In 1960, Nutrilite Corp. was able to register the microbial insecticide for control of the cabbage looper, and Carson (1962), in discussing chemical pesticides like DDT, was able to cite the use of biological insecticides like B.t. as a promising alternative. However, in the 1970s, USEPA began to run into public agitation about environmental problems, largely in response to fears raised by Carson (1962), and the Federal Environmental Pesticides Control Act was passed in 1972. Nutrilite's experimental use permit was withdrawn, additional data were demanded, and ultimately, the company abandoned all research on B.t. While B.t. has been "picked up" by other research organisations, similar problems have occurred with insect sex pheromones, juvenile and anti-juvenile hormones, and various other bacterial and viral diseases.

In addition to education and training on safe use, one of the most promising areas for circumvention of the problems of current pesticides is the development of new materials with new methods to reduce host damage, particularly when compatible with additional pest management tactics. These 4th generation, biorational pesticides, offer new modes of action with less environmental disruption. For example, fenoxycarb is a "juvenoid" insect growth regulator which helps control pest populations of the mining moth in Japanese apple orchards in two phases, initially by fenoxycarb and secondly by the native endoparasitic hymenopterans which begin building up in the second season. Such an approach has the added advantage of helping to delay resistance (Dorn, 1992).

Recent advances in the understanding of insect ecology, biology, physiology, and biochemistry are providing new opportunities for insect control (NRC, 1989). Increased knowledge of such insect hormones as brain hormone, moulting hormones, and juvenile hormone has made it possible to synthesise them. Introduction of devices that emit synthetic hormones offers the potential to disrupt normal highly insectselective functions such as breeding, growth, and moulting, thus controlling the pest populations. Insect pheromones are used commercially to monitor, detect, and predict insect populations and to control several insect pest species on a variety of crops.

\section{Increased population pressure}

Dollacker (1991) concluded that agriculture will have to become more intensive, particularly in those areas of rapidly expanding populations. He cited FAO figures on world population and land, whereby in 1965 there was 0.4 ha per person versus only 0.27 ha per person in 1988. He noted that food must not only be increased but it must be safeguarded as well.

In 1988, world food production was approximately 4.3 billion metric tonnes, twice as much as the production in 1963, only 25 years earlier (Borlaug, 1990). In spite of the doubling of food production, some 950 million people, mostly in low-income countries, had food intakes below the critical minimum for adequate health. World population is predicted to reach 6.1 billion by the year 2000 and 8.2 billion by 2025 . Even with no increase in nutrient intake per caput, world population will demand a doubling of food production over that of 1988 by the 
year 2025. Borlaug (1990) pointed out that about $80 \%$ of the projected population increase will reside in those low-income and food-deficit countries of Africa, Asia and Latin America.

The most promising approach to meeting the food demands of such increased population is intensification of production. However, intensification of production will lead to intensification of pest problems. A sustainable crop protection strategy, such as IPM, which utilises all available tactics, including "modern" pesticides, must be used.

\section{Availability of practical IPM programmes and IPM- compatible, alternative control tactics}

A follow-up survey on a training session on pest monitoring in the Philippines showed that adoption of IPM was low because the method is tedious, time consuming, requires new skills, and has marginal benefits (Medina et al., 1992). In a subsequent study to modify the system, it was concluded that the count and record system was too advanced for the capabilities and needs of farmers. A more effective system was developed based on common agrarian practices. Clearly, the failure and complexities of impractical IPM systems, particularly monitoring and determination of crop loss and economic thresholds will discourage the adoption of the IPM approach and encourage over-reliance on single tactics such as the use of pesticides.

An increasing demand for cabbage in Indonesia, as a result of rapid population growth, a rising GNP, and desire for a better diet, led to increased use of pesticides. Up to 16 applications per season were made at 4-6-day intervals. Pesticides represented $30 \%$ of the production costs. When education and training in IPM was introduced, sampling methods were improved following pilot programmes and the number of applications was reduced to $2-3$ per season (Irbansyah et al., 1992).

The use of resistant crop varieties offers an environment-friendly crop protection tactic that requires a minimum of extension inputs. Unfortunately, only few new varieties are being released, and these are intended for monocultural markets rather than for the less profitable, mixed cropping systems used on small farms. However, genetic engineering technology promises to accelerate breeding for pest resistance.

Most pests are prevented from causing excessive crop losses by natural enemies. However, scientists have identified successful and cost-effective biological methods of control for many crops by the introduction of non-endemic predators or parasites and the augmentation of endemic natural enemies. The success of such programmes can have significant impacts on the amount of pesticides required for crop protection. Introduction of parasites for the control of alfalfa weevil in the northeastern United States reduced the acreage previously receiving chemical applications by $73 \%$ (NRC, 1989).

Cultural control practices represent the third cornerstone of biointensive IPM. While pesticide use may play a greater role in the absence of suitable resistant plant varieties or classical and augmentative biological control tactics, the reverse is often the case with cultural controls. Cultural control methods should represent the first step in the development of local IPM programmes; however, due to the time and labour constraints involved in their use, they are often replaced with the pesticide tactic. Nevertheless, they are dependable and even partial control will reduce dependence on chemical pesticides. For example, if maize is planted early in the first rains season in Ghana, noadditional control with pesticides is required (Kumar, 1984). Mixed cropping, the normal practice among small-scale farmers throughout the tropics, affords many advantages, not the least of which is reduced pest damage. The maxim that diversity creates stability has received some criticism, and Risch et al. (1983), investigated its validity relative to crop protection in agriculture. They concluded that there existed striking evidence that diversification does lead to lower pest incidence. It has been cautioned (Matteson et al., 1984), however, that the risk of polyculture (i.e. mixed cropping) may outweigh the benefits and each particular situation must be evaluated independently. For example, it is now well known that small-scale farmers diversify crops in traditional farming systems to reduce risks and ensure production of cash and food crops, but that traditional intercropping makes the use of inputs such as pesticides very difficult (Okigbo, 1991).

Thus, while many cultural tactics do not lend themselves well to large monocultural farming systems, they do continue to fit the social and economic needs of the small farmer. Regrettably, the "lure" of chemical pesticides is gradually eroding the indigenous crop protection knowledge of cultural tactics, and unless they are documented and extension services personnel are trained in their use, they may become lost and less available just like IPM tactics.

\section{Innovative technologies}

Biotechnology and the introduction of resistant genes into commercial plant varieties is envisioned by some to be the answer to crop protection problems. Clearly, they must be unaware of similar claims 
made many times throughout history and the miraculous adaptability of microorganisms and insects. However, a host of what might be termed innovative technologies that have or will prove highly effective in curtailing the use of pesticides in IPM systems are in place, or on the horizon. Examples include male sterilisation of the screw-worm, breeding and release of genetically altered species that can mate with native pests and produce non-viable offspring, mating confusion with sex pheromone releases, and the use of the NGU trap in Kenya for the control of the tsetse fly. While these approaches can significantly reduce pesticide use, particularly when used in combination with other control tactics, they are often extremely selective in action, depend on long-term development, are too few in number, are geared to large-scale agriculture, and do not preclude the development of resistance.

\section{Constraints to the use of pesticides in pest management}

One of the most frequently cited references on pest-induced crop losses is that of Cramer (1967). He estimated losses due to insects during production at $13.8 \%$, those due to diseases at $11.6 \%$ and those due to weeds at $9.5 \%$. He failed to take into consideration a number of constraints to pesticide use, however, when he concluded that application of modern pesticides in routine programmes on all farms would very quickly put an end to most of the shortages in world food supply.

Certainly, the most difficult problem being faced in pesticide management is that of pesticide resistance. The first case of resistance to pesticides was detected in 1914 and now nearly 500 cases of resistance in insects and mites are recorded (Rousch and Tabashnik, 1990; Schulten, 1990 ). Schulten (1990) also noted that increasing instances of resistance are found among diseases, weeds, nematodes and rodents. He cited Georghiou (1986), who had observed that among the arthropods, $59 \%$ of the cases are of agricultural importance, $38 \%$ of veterinary or medical importance, and $3 \%$ are parasitoids and predators. The development of resistance impacts on the changing role of pesticides in IPM by reducing the number of pesticides that can be effectively used. This has led to more applications and higher dosages and has thus increased the cost of pest control and the contamination of the environment (Schulten, 1987). He also noted that resistance has discouraged the pesticide industry from developing more efficient and more target-oriented, or selective pesticides. As pointed out by Metcalf (1980), resistance to insecticide is not only a disaster to present methods of insect control, but it also prejudices the application of some of the most useful insecticides in future IPM programmes, thus making insect pest resistance the greatest single problem facing applied entomology.

The basic components of programmes to reduce resistance development include reduced selection pressure and insecticide management to choose the optimal sequence of insecticides used. The use of mixtures is often recommended as a means of delaying build-up in resistance. While such strategies may be useful if used properly, there exists great danger if they are used arbitrarily at the farm level. Wisely developed mixtures can simulate insect control with natural plant products which offer a mixture of different allelochemicals (Dorn, 1992).

The use of microbial insecticides which is considered to be a safer and more sound approach to insect control, is not exempt from the problem of resistance. Resistance is already showing up among some of the newer strains and in fact there is danger that if the gene for B.t. toxicity is introduced into plants, selection pressure will be greatly increased and resistance developed even more rapidly.

Malaria is a major global health problem and is specifically an important cause of child mortality in Africa. Where the vector is susceptible, DDT is preferred because it is cheap and environmentally safe for indoor use. Unfortunately, resistance is developing to both DDT and malathion, primarily due to agricultural use in many areas.

Environmental hazards of pesticides are well known, largely through the efforts of Rachel Carson's Silent Spring (Carson, 1962). Certainly, the persistence and biomagnification of materials such as Paris green, lead arsenate and the synthetic chlorinated hydrocarbons are clearly demonstrated to cause environmental problems; solution of these problems has had a major impact on the role of such pesticides in pest management programmes. Other compounds, less persistent but highly toxic to wildlife, often can still be used with restrictions or changes in formulation. In many third world countries, the public health constraints of pesticides seldom play a major role in their use when the small-farm household is facing possible starvation. Certainly, environmental hazard constraints would be of even less concern, making it incumbent on the international community to lead the way on locally adapted, environmentally benign, IPM programmes for third world small-scale farmers.

One of the more serious constraints of pesticides is their impact on beneficial organisms, i.e., parasites and predators. Metcalf (1980) discussed two types of resurgence. The first is a resurgence of pest populations that were originally suppressed by insecticide application and the second is the outbreak 
of new pest species that were previously held under control by natural enemies. It is precisely this nonselectivity of the broad-spectrum insecticides that has forced their removal from our shrinking arsenal of pesticide choices in IPM programmes. The solution obviously necessitates avoidance of broadspectrum insecticides and adoption of appropriate pesticide management to ensure judicious use of pesticides (Metcalf, 1980).

Clearly, pesticide-associated, public health problems, either actual or perceived, play a major role in the development and selection of pesticides used in crop protection. Estimates of pesticide poisoning in 1974 consisted of 500,000 acute pesticide poisoning with 900 or more deaths, of which $99 \%$ were in the Third World (Wasilewski, 1987). A more recent WHO estimate consists of 1.1 million cases per year, of which 20,000 are fatal (Anon, 1991). While it is not possible to determine accurately the extent of death and illness caused by the misuse of pesticides, certainly the presence of such large quantities of biocides assures large numbers of accidental, homicidal, and suicidal casualties beyond the hazards of normal use (Metcalf, 1980). Human toxicity of pesticides is a highly emotional and controversial issue which is not pertinent to this discussion. Suffice it to say, however, that human toxicity has a major impact on the creation of more stringent requirements for registration of new compounds, which further restricts choices needed in the development of IPM programmes. On the positive side, and in contrast to the problem with resistance, instances of accidental poisoning are preventable.

While pesticide disposal is the major concern in developed countries, the problem in developing countries is pesticide poisoning. As the amount used increases, so will the poisoning problems unless there is a concerted effort for the technology of safety (Davies and Lee, 1987). Solutions such as "banning pesticides" are not so simple, since in many countries the absence of pesticides means the absence of farming and farmers actually fear the curtailing of pesticide use by governments. An "agromedical approach" has been suggested as a solution to many of the healthrelated problems associated with pesticide use (Davies et al., 1982). This approach deals with pesticide management beginning with the importation, or manufacture through formulation, distribution and storage, to the use of chemicals and disposal of containers and unwanted materials. In-country (-region) agromedical teams would draw widely on information available in the world literature, and through careful analysis and synthesis, apply that information to local conditions. They would then devise the appropriate technology for implementation of laws and regulations, the monitoring of the chemicals used, how they are used, and their interface with human health and the environment.

A survey carried out in 1986 in Kendu Bay/ Oyugis, western Kenya, revealed that about $40 \%$ of the farmers sampled used chemical pesticides (Saxena et al., 1990). Forty per cent did not use them because they lacked proper knowledge on their use, while $18 \%$ avoided them for economic reasons. In Kenya, most information on pesticide use comes through exchange of experiences or through the agricultural chemical industry and their outlets. Information from the Pest Control Board or research organisations is not effectively disseminated and there is a need to develop a training programme for both the extension service and farmers with the purpose of transferring such knowledge (Kibata, 1992).

In addition to the classic constraints to pesticide use, there exists a number which are peculiar to the traditional agriculture sector in third world countries, which impacts on their use. In contrast to the opinion of some, that pesticide use is a simplistic approach, appropriate pesticide management, when used in the IPM mode, is a highly complex and sophisticated element of crop protection. Therein lies the problem for the small-farm sector.Proper pesticide use requires correct identification of the target complex, an index of population density, an ability to predict density trends, ability to identify time of action, and selection of the right treatment, dosage, and timing. These requirements are often well beyond the capabilities of the average small-scale farmer and, unfortunately, no one is attempting to simplify the technology. In most countries, there are few, if any, research organisations studying small-scale crop protection problems.

A rapid escalation in the costs of pesticides is resulting from linkages to the increasing costs of petroleum, the sophisticated chemical structures of the newer, more effective compounds, and the multifold increases in costs for development due to inflation as well as the more stringent requirements forregistration (Metcalf, 1980). Metcalf (1980) noted that doubling-time of the cost of pesticides was about 3.2 years based on increases observed in the $1970 \mathrm{~s}$. Clearly, it will continue to be difficult and expensive to develop new pesticides and there will be a decrease in the numbers of materials available for use in the new IPM programmes. While cost is a major concern to all pesticide users, it is of particular concern to small-scale growers in developing countries and to those countries already suffering serious shortages in foreign exchange. Many of these countries simply 
lack the economic resources to purchase expensive, modern, safer, and more effective pesticides. It has been suggested that in some cases it may be wiser to teach the local people to use the current pesticides safely, than to introduce newer, more expensive and possibly more hazardous compounds.

On a local basis, economics as a reason for not using chemical pesticides is second only to lack of knowledge on their use (Saxena et al., 1990). Subsistence farmers simply lack the necessary resources to purchase the chemicals profitable to their farming, i.e., those not entering trade. Further, such financial resources may not be available at the right time. Women, who are responsible for much of the farm operations, do not have control of cash. A further complication due to lack of financial resources is the selection of the cheaper, broad-spectrum chemicals, such as the chlorinated hydrocarbons.

Pesticide costs for vector control are estimated at $\$ 100$ million annually, with increasing costs due to resistance and the selection of alternative, less persistent materials. Chemical control of the adult tsetse flies remains the major control tactic. Single applications of the more persistent chlorinated hydrocarbons were effective and possible, but the multiple applications of newer, less persistent materials are expensive and uneconomical. Their costs compete with other high-priority needs for foreign exchange. Clearly, alternative strategies must be developed (Schaefers, 1990).

A common constraint to the use of pesticides is their non-availability when needed. This is usually due to bureaucratic inefficiencies or transport-related problems. Such constraints will encourage the use of altemative tactics, including use of the more traditional crop protection practices.

Most third world countries lack the necessary extension support for the development and training in integrated pest management, or pesticide management, for assisting small-scale farmers. Van Huis et al. (1982), concluded that $80 \%$ of the applications recommended for pest control in maize in Nicaragua were unnecessary and that agents needed more training in the use of economic thresholds. Often, the only source of information is from multinational pesticide companies and their dealers, whose priorities may differ from those of the farmer or the environmentalist. The numbers of pesticide applications by large-scale maize growers in Nicaragua can actually be predicted from the various levels of technical assistance, of which visits by selling agents are most important (Van Huis et al., 1982). Proper use of the pesticide tactic is complex and highly extension dependent. The absence of a suitable agricultural infrastructure in many developing countries represents a major deterrent to the use of pesticides in pest management programmes.

Changes in cultural practices, e.g. changing from mixed cropping to monocultures and the use of more susceptible plant hybrids, has resulted in major increases in the use of pesticides in IPM programmes.

One reason for the rapid growth in the use of pesticides worldwide has been the "Green Revolution" (Brown et al., 1990). The high increase in losses due to pests in spite of greatly increased pesticide use, is largely attributed to intensification of agriculture with the resultant increase in pest problems, along with the abandonment of rotations, reduction of field sanitation, reduced tillage with more crop residues left on the land, and higher cosmetic standards for fruits and vegetables (Pimentel, 1992). Further, application technology is changing and can have significant impacts on the amounts of pesticides used and the amounts reaching the target pests.

\section{CHANGING PATTERNS IN PESTICIDE USE IN TROPICAL REGIONS}

\section{A profile of current use}

While pesticides have been used extensively in developing countries since the 1950s, their use was largely confined to green revolution technologies and the control of vector-borne diseases (Anon, 1988). By the early 1980 s, these countries were thought to use 10 to $25 \%$ of the world pesticide supply; however, about one-third of the crops were still lost to pests each year and malaria alone affected over 100 million people annually (Bottrell, 1983). Pesticide use has increased rapidly in developing countries in recent years, and is presently valued at 4 thousand million US dollars per year (Anon, 1991). Third World countries used $26 \%$ of the world pesticide production in 1990 . The fact that $55 \%$ of the agricultural land in the world is located in Third World countries shows that the use of pesticides in these countries is relatively much lower than that in industrialised countries (Dollacker, 1991). Richardson (1990) reported that the pesticide used per hectare of farmland was $10,790 \mathrm{~g}$ in Japan; $1870 \mathrm{~g}$ in Europe; $1490 \mathrm{~g}$ in the $\mathrm{US} ; 220 \mathrm{~g}$ in Latin America and $127 \mathrm{~g}$ in Africa.

Many developing countries including India, China, Bangladesh, and Indonesia are participating in the global expansion of agricultural output involving the green revolution and its associated biotechnology. Thus, the value (in dollars) of pesticide imports to Asia more than tripled between 1971/3 
and $1983 / 5$. The trend is for more, rather than less, use of agricultural chemicals in the developing world (Carter, 1989).

The fastest-growing pesticide markets are India, Brazil, China, and Spain (Brosten and Simmonds, 1989). It is estimated that about US $\$ 20$ billion is spent on pesticides throughout the world and involves an estimated 2.5 million tons of pesticides annually. Of the $24 \%$ reaching the developing countries, about $12 \%$ goes to Asia, $8 \%$ to Latin America and $4 \%$ to Africa (Anon, 1990). Statistical information on pesticide use in Africa is hard to find. Estimates indicate that African countries import about US $\$ 500$ million worth of pesticides annually (FAO, 1990).

Significant changes in pesticide use during the last 30 years

The quantity of pesticides used in Africa increased 5-fold during the 15-year period following the mid1960s (Anon,1981). Currently, the African and West Asian pesticide market is valued at US $\$ 1.6$ billion and reflects a $23 \%$ increase over the last 5 years. The quantity used in Colombia increased 4-fold during the 10-year period following the mid 60s (Gonzalez, 1976) and increased even more in Brazil during the same period (Davies etal., 1982). The Latin American pesticide market is presently valued at US $\$ 3.3$ billion and reflects a $38 \%$ increase over the last 5 years. Southeast Asia, a heavy user of pesticides, has a pesticide market valued at US $\$ 7.7$ billion and represents a $31 \%$ increase over the last 5 years.

Ninety per cent of the pesticides imported into Kenya are for agricultural use. For southern Africa it is estimated that $80 \%$ of the pesticides are used in agriculture, $15 \%$ in animal health and less than $5 \%$ for public health. Exceptions would be in Botswana and Namibia where a larger share is used in animal health (Van der Wulp, 1990).

Of the 2.5 million tons of pesticide used worldwide, $50-60 \%$ are herbicides, $20-30 \%$ are insecticides, and 10-20\% are fungicides (Pimentel, 1992). Much variation exists in these "estimated" statistics and range widely according to the development status of the country and the major crops and associated pest problems. While herbicides occupy $50 \%$ of the pesticide market in industrialised countries, their use in developing countries is lower and dependent on income level (Dollacker, 1991). About $18 \%$ of low income farmers use herbicides while about $40 \%$ of the medium and relatively higher income farmers use them. Insecticides represent $24 \%$ of the market in industrialised countries and 32-69\% in developing countries, again depending on income.
Fungicides represent $22 \%$ of the market in industrialised countries and $12-26 \%$ in developing countries. In East Africa, most of the agricultural pesticides are insecticides, followed by fungicides and herbicides in terms of value and percentage imported (Kibata, 1992). Similarly, throughout West Africa, the various pesticides are mainly insecticides, followed by herbicides and fungicides, and then rodenticides and nematicides (FAO, 1990). In Barbados, insecticides represented $59 \%$ of the pesticides used; in Guyana, herbicides represented $67 \%$ of the pesticides used and in Jamaica, $68 \%$ of the pesticides used were fungicides. Clearly, the category depends on the major crops grown and their key pest problems. In Algeria, where cereals are the major food crops, the increase in pesticide use from 1980 to 1985 was $150 \%$ for insectides, $135 \%$ for fungicides and $950 \%$ for herbicides.

\section{Use patterns on cash crops vs subsistence crops}

Crop protection measures for cash crops are primarily aimed at optimising yields and farm profits. Cash crop systems are usually characterised by extended acreages, monocultures, no rotation, intensive use of farm chemicals including pesticides; plant varieties are selected for high yield, are genetically homogeneous and less resistant to diseases and insects (Anon, 1991).

Until recent years, over $80 \%$ of the insecticides used in Central America were applied to cotton. Of the total quantity of herbicides, $32 \%$ were used on sugarcane, $25 \%$ on rice, $18 \%$ on cotton, $14 \%$ on banana, and $10 \%$ on other crops. Over $62 \%$ of the fungicides were used on bananas (Burton and Philogene, 1985). Pesticides are now an integral part of rural life in Central America. Dramatic yield increases, government and international aid and credit, marketing practices of multinationals, all have encouraged economic and psychological dependence on pesticides. The use is particularly acute in Central American agriculture on cotton, banana, coffee, winter vegetables, and sugarcane (Dowling, 1990).

Pesticide use is also growing in Africa, mostly for cash crops such as cotton (in Egypt and the Sudan). Other crops such as cacao, rubber, and oil palm have lower pesticide requirements. North African countries are getting more involved in growing fruit trees, which require intensive pest management.

In Guatemala, the average annual number of applications of insecticides on cotton has increased from 8 to 40 , and the quantity used is among the highest in the world. In some areas, pesticides comprise $50 \%$ of the costs of agricultural production (Leonard, 1987). 
The typical pesticide treadmill syndrome is common to cotton production worldwide. When Nicaragua first investigated the IPM approach in the early 1970 s, the average number of applications per season was 28 . With international assistance, IPM programmes were sequentially developed and implemented resulting in a 33\% reduction in pesticide use. It is unfortunate that as a result of marketing and political problems in the 1970 s, the IPM programmes in Nicaragua are once more in jeopardy (Hansen, 1987). A similar scenario occurred in Peru during the 1940s and 1950s (Brader, 1979). Chemical control of tobacco budworm in 1939 resulted in an increase in the cotton aphid. Numbers of applications of arsenicals and nicotine sulphate increased, resulting in the destruction of natural enemies and crop failures by 1949. A variety of management tactics, including the use of economic thresholds and proper use of chemicals, were partially implemented but with the advent of synthetic insecticides, a greater increase in the numbers of pests occurred. Resistance to the chlorinated hydrocarbons DDT and BHC developed. By 1956, yields had dropped to record lows and numbers of pesticide applications reached 16. Early IPM proposals were reimplemented and yields peaked while numbers of pesticide applications dropped to 2.35 per season. As with Nicaragua, political instability threatens the management system and the danger of returning to a pesticide-dependent scheme persists. On the plus side, farmers' knowledge of integrated pest management has come about largely through their acquaintance with its implementation in cotton.

A classic example of pesticide misuse in cash crop production in Africa is that of cotton production on the Gezira Scheme in the Sudan (Schaefers, 1990). The scheme produces about $75 \%$ of Sudan's cotton, which earns $60 \%$ of its foreign exchange. Pesticides were first used in the Gezira in 1941 to control the cotton leafhopper. An $11 \%$ yield increase resulted and the race was on. In 1944, DDT was used with resultant yield increases of up to $40 \%$, followed by the use of lindane and dieldrin. The area receiving DDT for leafhopper control increased from 1650 feddans (=42 ha) in 1945 to 182,000 feddans in 1951 . Parathion was added to a DDT mixture, followed by the introduction of endrin and then dimethoate for the control of whitefly in the early 1960s. In spite of the greatly increased pesticide use during the 1970s, (less than one spray per season in 1960 to eight sprays per season in 1980) cotton yields continued to decline. Of particular concern was the development of resistance to dimethoate by the whitefly. In the $1980 \mathrm{~s}$, steps were taken to stop packaged programmes, phase out DDT, and develop better pest management. Yields have begun to improve but pest control still constitutes a large percentage of the production costs.

The use of the IPM approach is beginning to change this picture. In Brazil, soybean production increased 7-fold during the 1970 s with a resultant intensification of pest problems. Monitoring systems were developed, economic thresholds were utilised and selective pesticides were used. That pilot programme, which relied heavily on technical and financial assistance from various international organisations, resulted in a reduction of pesticide use of $93 \%$ (Hansen, 1987).

Bananas represent the second most extensively cultivated fruit in the world, grown both as a staple food crop and as a major cash crop. In the late $1940 \mathrm{~s}$, United Fruit began spraying bananas with dieldrin. Resistance to dieldrin developed, natural enemies were killed, secondary pests emerged and a succession of newer pesticides were tried with little success. Finally, economic thresholds were determined based on a higher tolerance of plant injury than earlier thought, and pesticide use was reduced by $75 \%$ (Hansen, 1987 ).

Pesticides are used by large-scale maize growers in Nicaragua (Van Huis et al., 1982). In 1982 they were primarily using trichlorphon. They were also using a great variety of materials and numbers of applications were also high as a result of their largescale cultivation of cotton. Van Huis et al. (1982) concluded that due to low field losses, cumbersome pest scouting methods, and ineffective applications, about $50-60 \%$ of the larger farms on the coast applied pesticides unnecessarily and with another $30 \%$, the effectiveness of the treatments was doubtful.

Rice production in Southeast Asia presents another example of reductions in pesticide use through an enlightened IPM approach (Anon, 1988). The release of high-yielding rice varieties by IRRI gave good returns initially but their genetic uniformity made them susceptible to numerous pests in a short time. Starting in the early 1950 s, pesticides supplied by the Government provided some relief against two major pests but shortly, problems with the brown planthopper became serious. The introduction of more resistant varieties, use of economic thresholds, and proper doses proved successful and pesticide costs dropped by $50 \%$ (Hansen, 1987).

Any crop protection measures applied in subsistence farming are primarily for securing food production. Insects and diseases, which are usually endemic, are controlled by natural enemies, hostplant resistance, and certain weather conditions (Anon, 1991). 
Less than one-third of all the agricultural cropland in the world is treated with some kind of pesticide (Pimentel, 1992). This is because subsistence farmers, who are the major food producers in the third world, do not use pesticides.

Commercial growers in Costa Rica, El Salvador, and Nicaragua spent between 45 and $55 \%$ of their budgets on pesticides while small-scale producers spent 15-30\% (Anon, 1988). Farmers in Nicaragua who abstain from pesticide use do so because they do not consider pest problems serious (57\% of farmers sampled), they find the pesticides too expensive (24\%), or they simply lack experience in their use (22\%) (Van Huis et al., 1982). In case of severe outbreak, however, $75 \%$ would use pesticides and $53 \%$ would try to get the technical assistance needed. During 1974-78, about $2 \%$ of the farmers used fungicides on their food grains, and while about $50 \%$ of the farmers with more than 14 ha used herbicides, those with smaller farms rarely used them.

Cassava is a major staple food in $80 \%$ of Africa and many other parts of the world. Since it is mainly grown as a subsistence crop, yield failure results in starvation rather than economic loss. The introduction of the cassava mealybug and the green mite into Africa in 1970 resulted in yield losses of 5-80\%, thus threatening the health and survival of millions of people in Africa. Pesticides were never used on this crop for a variety of economic, social and logistical reasons and scientists turned to IPM for a solution. The possibility of using biological control measures was investigated and a major breakthrough was reported while studies continue on the use of natural enemies and tolerant varieties for control of the green mite (Herren and Neuenschwander, 1991).

Pesticides will continue to be used on high-value cash crops, but generally are less cost-efficient on low-value crops such as millet, sorghum, or cassava. In Senegal, for example, it is reported that cotton accounts for over $48 \%$ of pesticide use while vegetables take $1.3 \%$ and sorghum/millet only $0.27 \%$.

Pesticide use in Kenya is also more applicable to the large-scale cash crop production rather than the smallholder food crop or subsistence farming (Kibata, 1992). However, the smallholder sector is undergoing fast changes towards a cash cropeconomy, especially in horticultural crops where increasing production is resulting in higher use and demand for agrochemicals, including pesticides. This smallholder sector currently represents $83.5 \%$ of the total cropland in Kenya and is expected to grow steadily over the next few years as large farms are further sub-divided. Horticulture is a steadily growing industry and a major consumer of pesticides, although, currently the actual quantity used per crop is low. Similar changes are occurring in
Central America, the Caribbean, Uganda, and elsewhere in the tropics.

\section{International or migratory pest problems}

The control of migratory pest outbreaks is a major problem because of the sheer magnitude and logistics of controloperations. The desert locust has an invasion area of 28.5 million $\mathrm{km}^{2}$ in North Africa, the Middle East, and Asia, equalling about $20 \%$ of the earth's land surface. Crop protection during outbreaks remains almost entirely dependent on the use of pesticides. Significant quantities of pesticides were brought into Africa for the control of locust outbreaks in the period $1986-89$; most of the pesticides were selected and provided by donors. The selection and acceptance of pesticides is of utmost importance because of the areas sprayed and the amounts used. Acceptance of selected pesticides is not uniform and is subject to considerable controversy. The most commonly used insecticides (in the USA) are propoxur and fenitrothion.

Since outbreaks or plagues have never been "broken", their management results from either prevention or strategies involving crop protection. Theoretically, at least, prevention can be accomplished, particularly with the advantages of modern technologies and shared costs for surveillance. Such advantages would permit control in the recession areas prior to outbreak. Some controversy exists over the relative value of massive aerial spraying to "control" the pests versus applied crop protection. Clearly, there exist situations where each becomes more appropriate.

In its assistance programmes for locust control in Africa, USAID bans the use of dieldrin, BHC, DDT and Lindane. However, FAO argues that while the half-life of dieldrin is 3 years in the temperate zones, it is only 4 months in the tropics. It retains a useful residual toxicity for about 20 days where malathion and fenitrothion have ineffectively short residual toxicities. Further, FAO contends that the limited amount of dieldrin used, $30 \mathrm{~g} / \mathrm{ha}$ on about $10 \%$ of the outbreak area is acceptable. In this approach the material is placed in band treatments and the nymphs migrate through the bands of insecticide, whereas the organophosphates are sprayed over extensive areas and must come in contact with the locusts almost immediately.

\section{Based on human or animal health problems}

Some 600 million people suffer from diseases transmitted by vectors, most of which are arthropods (Anon, 1991). Diseases are so serious throughout the 
tropics that public health insecticides may outvalue those used for agriculture. For example, St. Lucia uses 19,000 litres of oil and malariol, plus $3665 \mathrm{~kg}$ of Abate per annum, compared to 3332 litres of liquid insecticides and $840 \mathrm{~kg}$ of powders for agricultural purposes. Malaria is experiencing a resurgence in rural areas of Belize, Honduras, Nicaragua and Guatemala, and an intensified programme to control the disease-carrying mosquitoes was reported to be increasing the use of DDT substantially (Leonard, 1987), in spite of observed resistance against this insecticide (Chapin and Wasserstrom, 1983). Pesticides directly benefited public health, not only through the elimination of vectors of human and animal diseases, but through the opening up of lands for habitation and agriculture that were not previously usable.

In eastern and southern Africa, because of the importance of the livestock sector, relatively large amounts of acaricides are used for tick control. Tsetse control programmes have historically involved the use of large amounts of aerially applied insecticides. However, this picture is changing somewhat as a result of the successful use of traps in such countries as Kenya, Zambia and Malawi. In other countries where the flies have a different behaviour, such traps are less effective.

Housefly resistance to DDT was observed in Italy and the United States as early as 1948; in 1949, DDTresistant mosquitoes were found in the US. By 1980 , resistant strains of some 414 arthropod pests, of which 152 are of medical importance, had been noted (Georghiou, 1980). In dealing with the problem of resistance, a number of organochlorine, organophosphate, and carbamate insecticides were developed and marketed. More currently, Baytex (fenthion), Abate (temephos), and fogging with malathion and diesel has been used. A number of them are much more acutely toxic than DDT, thus directly contributing to the other problems of human and animal poisonings (Davies et al., 1982). Interestingly, while DDT is banned in 29 countries and severely restricted in 23 others, it is still being used for mosquito control and in fact remains recommended by WHO. Currently used materials include Baytex (fenthion), Abate (temephos), and more recently, the pyrethroid Icon (lambdacyhalothrin).

\section{Changes in agricultural commodities}

As an example of the impact of changing commodities on pesticide use, there was a great increase in vegetable production in the 1960s in Barbados, which resulted in an increase in pest and pesticide problems, while there was a decrease in sugarcane and root crops production which required lower pesticide input.

\section{Mode of action of pesticides}

History clearly demonstrates that pesticide-based programmes largely failed due to the use of broadspectrum inorganic and synthetic organochlorine toxicants. This resulted in destruction of natural enemies and, as is characteristic of even selective pesticides, the development of resistance. Cocoa in East Malaysia was attacked by a few species of borers in the 1950s (Brader, 1979). Spraying with dieldrin or DDT was started in 1959 after which numerous other pests became noticeable. Resistance began to develop and spraying was completely stopped in 1961. Populations of most pests declined due to increased parasitism but borers and the bagworm persisted. The selective use, i.e., local application only, of dieldrin along with elimination of an alternative host reduced damage to below $0.5 \%$. Dipterex (trichlorphon) was found to be an effective and selective insecticide against bagworm. A similar situation occurred in oil palm in West Malaysia. Control of bagworms in the late 1950 s was accomplished with broad-spectrum contact insecticides. Parasites were re-established along with the use of an economic threshold of 10 larvae/frond, and the careful use of the selective insecticide trichlorphon. As a result, the problem was significantly reduced.

In addition to selective toxicity of various compounds and the selective use of less selective materials, progress is being made on the development of more pesticide-tolerant natural enemies.

\section{THE FUTURE OF PESTICIDE USE IN DEVELOPING COUNTRIES IN THE TROPICS, THEIR NEED AND EXPECTED IMPACTS}

\section{Direction and intensity of pesticide use}

The future of plant protection will depend on the continuation of existing pest control tactics and technology including the use of those powerful tools, pesticides. Nickle (1973), stated that the level of (agricultural) productivity required for future populations would be impossible without the use of tools such as pesticides. While he may have reason to rephrase his pronouncement in view of today's outcry by an increasingly environmentally conscious society, he remains technically correct. Certainly if we are to maintain a sustainable integrated pest management 
programme at higher than subsistence levels, we must intelligently integrate as many strategies as possible, including that of synthetic chemical crop protectants. We have learned that pests cannot be controlled by these products alone, and it is also increasingly apparent that they cannot be controlled by alternative tactics alone.

Some consider that pesticide use for small-farm peasant agriculture is not a future option, but an immediate urgency. The developing world is on the threshold of large increases in the use of pesticides and they offer an opportunity for a quantum leap $(50 \%)$ in food production (Wittwer, 1979). Wittwer predicts that pesticides will be used more sparingly in the IPM era and the costs within an IPM system will be lower than those where pesticides alone are used. He was of the opinion that pesticides will continue as an essential, perhaps the major, component of IPM systems and must be available when needed. He noted that chemical pesticides were part of all producer-supported IPM systems and projected that use of pesticides would continue worldwide with the greatest increases occurring in Africa, Latin America, the Far East, the Middle East, and Southeast Asia in that order.

Borlaug (1990) concluded that yields can be increased by $10-100 \%$ in Asia and Latin America and by up to $200 \%$ in sub-Saharan Africa with the right technology and modern production tools. Clearly, this target can only be met with the help of sustainable crop protection technology including enlightened pesticide management programmes.

Expenditures on pesticides in some countries were projected to at least double and possibly treble between 1985 and 1995. Most of this increase will occur in agriculture while vector control is expected to remain fairly constant. Developing countries are expected to contintue increasing both the absolute quantities they use and their proportion of the increasing global consumption (Anon, 1988). An FAO prognosis foresees a growth rate in pesticides of $4.5 \%$ a year on a worldwide scale (FAO, 1982). The rate of increase will be greatest in developing countries notwithstanding an increased awareness of the potential danger of pesticides and all ongoing activities to promote IPM practices (Schulten, 1987). The FAO publication, "Agriculture Towards 2000" (FAO, 1982) estimates that pesticide use in Africa will increase at all levels of agricultural production at $10 \%$ per year over the next decade. The growth rate for insecticides in Africa is estimated at $2 \%$ while fungicides and herbicides are expected to increase at rates of 8 and $15 \%$ respectively. The use of pesticides will increase in scope and size as agricultural production is intensified to provide food and surplus produce for local and export markets (Kibata, 1992).

While IPM and other alternative systems often require fewer pesticides on a per hectare basis, pesticides will remain routine and occasionally invaluable production inputs in most crops for the foreseeable future (NRC, 1989). Pesticide use in the third world is a matter of public controversy and debate which can only be settled through the promotion of suitable IPM programmes and the incorporation of intensified pesticide management.

\section{Qualitative changes}

Future recommendations for the pesticide industry include acceptance of lower profits, financing IPM research and extension in countries where national institutes are weak, utilising their marketing skills in the promotion of IPM, recognising that dealers/ merchants are primarily interested in making profits, and organising small-scale farmers so that they can benefit from knowledge as much as the large-scale farmers (Vorley, 1992).

There exists a clear trend of decline in the use of organochlorines in agriculture as a result of policies to phase them out due to environmental factors and risks posed by residues. The use of insecticides based on pyrethroids and organophosphates, as well as the use of herbicides, seem to be increasing (Van der Wulp, 1990). Pesticide use practices have changed also in the use of newer materials that are applied at much lower rates and older materials that are being used with much greater precision (NRC, 1989). Decreases in the amount and number of applications of insecticides have occurred in some situations such as in the cultivation of cotton and alfalfa. In others the numbers of applications have remained the same or increased while the volume of insecticides used has declined.

Since 1845 , the toxicity and biological effectiveness of pesticides have increased at least tenfold (Pimentel, 1992). For example, in 1945 DDT was applied at a rate of about $2 \mathrm{~kg} / \mathrm{ha}$. With the more potent insecticides available now, similar effective insect control is achieved with pyrethroids and aldicarb applied at 0.1 and $0.05 \mathrm{~kg} / \mathrm{ha}$, respectively.

\section{Manner of future use}

While the direction of pesticide development is clearly in the direction of low-risk materials, it may be necessary to create special situations whereby the higher risk materials may be used in special situations in special manner, placing them in a "prescriptive use" category. 


\section{REFERENCES}

Alford H. G. (1985) Classification, chemistry and toxicology of pesticides. In Pest and Pesticide Management inEast and Southern Africa (Edited by Jensen J., Stroud A. and Mukanyange J.), pp.109-111. USAID/REDSO/ESA, Nairobi.

Anonymous (1981) Poisons and peripheral people: Hazardous substances in the third world. Cultural Survival Inc. Newsletter 5, 1-8.

Anonymous(1988) Opportunities to assist developing countries in the proper use of agricultural and industrial chemicals. The Conservation Foundation. USAID, Washington, $101 \mathrm{pp}$.

Anonymous (1990) Facts and figures, International agricultural research. Rockefeller Foundation Report.

Anonymous (1991) Crop protection, vector control and pesticide use in developing countries. Ministry of Agriculture, Nature Management and Fisheries of the Netherlands. Report. Wageningen, $24 \mathrm{pp}$.

Borlaug N. E. (1990) The challenge of feeding 8 billion people. Farm Chemicals International $10,12$.

Bottrell D. (1983) Social problems in pest management in the tropics. Insect Sci. Applic. 4, 179-184.

Brader L. (1979) Integrated pest control in the developing world. Annu. Rev. Entomol. 24, 225-254.

Brader L. (1982) Recent trends of insect control in the tropics. Ent. exp. \& appl. 31, 111-120.

Brosten D. and Simmonds B. (1989) Inputs for the starving continent. Agrichemical Age 33, 6-7.

Brown L. R. et al. (1990) State of the World. Worldwatch Institute. Washington, DC.

Burton D. K. and Philogene B. J. R. (1985) An overview of pesticide usage in Latin America (KIN 6N5:1985). University of Ottawa.

Carson R. (1962) Silent Spring. Fawcett World Library, NY. 304 pp.

Carter H. O. (1989) Agricultural sustainability: An overview and research assessment. Calif. Agric. $37,16-18$.

Chapin G. and Wasserstrom R. (1983) Agricultural production and malaria resurgence in Central America and India. Nature 293, 181.

Cramer H. H. (1967) Plant protection and world crop production. Pflanzenschutz Nachr. 20, 1-524.

Davies J. E., Freed V. H., and Whittemore F. W. (1982) An agromedical approach to pesticide management, some health and environmental considerations. Univ. Miami, Miami, 320 pp.

Davies J. E. and Lee J. A. (1987) Changing profiles in human health effects of pesticides. In Pesticide Science and Biotechnology (Edited by Greenhalgh R. and Roberts T.R.), pp. 533-538. Blackwell Scientific Publications.

Dollacker A. (1991) Pesticides in the third world. Pflanzenschutz Nachr. 44, 89-100.

Dorn S. (1992) Stabilizing important agroecosystems: The contribution of juvenoids. In Papers Contributed by Ciba-Geigy. 19th Int. Cong. Entomology, Beijing, China.

Dowling K. (1990) Pesticide poisoning and preventive programmes in Nicaragua.ICET News 6, 3-4.

FAO (1982) Agriculture towards 2000. FAO Report 23.

FAO (1990) Report of the sub-regional workshop on pesticide management for western Africa . FAO, Regional Office for Africa.

Farrell K. R. (1990) Agricultural pest control alternatives. Calif. Agric. 44, 2.

Frisbie R. E. and Smith J. W. J. (1989) Biologically intensive integrated pest management: The future. Nat. Mtg. Entomol. Soc. Amer. Centennial Nat. Symp. Progress and Perspectives for the 21st Century. pp. 151-164.

GAO (1979) Better regulation of pesticide exports and pesticide residues in imported foods is essential. (Rep. No. CED-79-43).US Govt. Acct. Office, Washington DC.

Georghiou G. P. (1980) Insecticide resistance and prospects for its management. Residue Reviews. 76, 131-145.

Georghiou G. P. (1986) The magnitude of the resistance problem. In Pesticide Resistance: Strategies and Tactics. Nat. Acad. Press, Washington, DC. pp. 14-43.

GonzalezR. H. (1976)Crop protection in Latin America with special reference to integrated pest control. FAO Plant Protection Bulletin 24, 66-74.

Goodell G. (1984) Challenges to international pest management research and extension in the third world: Do we really want IPM to work? Bull. Entomol. Soc. Amer. 30, 18-26.

Hansen M. (1987) Escape from the pesticide treadmill: Alternatives to pesticides in developing countries. Institute for Consumer Policy Research, Consumers Union of the United States, $185 \mathrm{pp}$.

Haskell P.T. (1977) Integrated pest control and small farmer crop protection in developing countries. Outlook on Agriculture 9, 121-126.

Herren H. R. and Neuenschwander P. (1991) Biological control of cassava pests in Africa. Annu. Rev. Entomol. 36, 257-283.

Irbansyah B., Nevill D. J., Triwiyono A. and 
Sastrosiswojo S. (1992) The practical implementation of IPM on cabbage in Indonesia. In Papers Contributed by Ciba-Geigy. 19th Int. Cong. Entomology, Beijing.

Kibata G. B. (1985) Constraints in the implementation of Kenya's pesticide legislation. In Pesticide Management in East and Southern Africa (Edited by Jensen J.), pp. 80-82. USAID/REDSO/ESA, Nairobi, Kenya.

Kibata G. N. (1992) Pesticides in Kenya. Kenya Agric. Res. Inst. Mimeo.

Kumar R. (1984) Cultural Practices. Insect Pest Control with Special Reference to African Agriculture. Edward Arnold Ltd., London, pp. 73-87.

Leonard H. J. (1987) Natural resources and economic development in Central America. International Institute for Environment and Development, Washington, DC.

Matteson P.C., Altieri M. A. and Gange W. C. (1984) Modification of small farmer practices for better pest management. Annu. Rev. Entomol. 29, 383402.

Medina C. D., Velasco L. R. I. and Soriano J. S. J. (1992) Developing an insect monitoring system for rice farmers in the Philippines. In Papers Contributed by Ciba-Geigy. 19th Int. Cong. Entomol., Beijing.

Metcalf R. L. (1980) Changing role of insecticides in crop protection. Annu. Rev. Entomol. 25, 219-256.

Nickle J. L. (1973) Pest situations in changing agricultural systems, a review. Bull. Entomol. Soc. Amer. 19, 136-142.

NRC (1989) Alternative Agriculture. National Research Council, Board on Agriculture. Nat. Acad. Press, Washington.

Okigbo B. N. (1991) Development of sustainable agricultural systems in Africa; role of international agricultural research centers and national agricultural research systems. IITA Distinguished African Scientist Lecture Series. $66 \mathrm{pp}$.

Pimentel D. (1992) Pesticides and world food supply. In The Science of Global Change (Edited by Dunnette D. A. and O'Brien R. J.), pp. 309-323. American Chemical Society, Washington, DC.

Repetto R. (1985) Paying the price: Pesticide subsidies in developing countries. World Resources Institute Research Report 2. 27 pp.

Richardson L. (1990) Probing the "circle of poison". Agrichem. Age. 20-21.
Risch S. D., Andow D. and Altieri M. A. (1983) Agroecosystem diversity and pest control: Data, tentative conclusions, and new research directions. Environ. Entomol. 12, 625-629.

Rousch R. T. and Tabashnik B. E. (Eds.) (1990) Pesticide Resistance in Arthropods. Chapman and Hall, New York and London.

Saxena K. N., Pala Okeyo A., Seshu-Reddy K. V., Omolo E. O. and Ngode L. (1990) Insect pest management and socio-economic circumstances of small-scale farmers for food crop production in western Kenya: A case study. Insect Sci.Applic. $10,443-462$.

Schaefers G. A. (1990) Public sector pesticide use in Africa. J. Agric. Entomol. 7, 183-190.

Schulten G.' G. M. (1987) Challenges facing agricultural entomology in the tropics. Insect Sci. Applic. 8, 397-405.

Schulten G. G. M. (1990) Needs and constraints of integrated pest management in developing countries. Med. Fac. Landbouww. Rijksuniv. Gent. 55 (2a), 207-216.

Smith R. F. and Reynolds H. T. (1966) Principles, definitions and scope of integrated pest control. FAO Symposium on Integrated Pest Control. 1, 11-17.

Tucker W. (1978) Of mites and men. Harper's. August, 43-58.

USAID (1990) I. Integrated pest management: A.I.D. policy and implementation, II. Pesticide use and poisoning: A global view. US Agency for International Development Report to the US Congress. Washington.

Van der Wulp H. (1990) The state of pesticide management in the SADCCregion. FAO/SADCC Subregional WorkshoponPesticide Management. FAO Regional Office for Africa.

Van Huis A., Nauta R. S. and Vulto M. E. (1982) Traditional pest management in maize in Nicaragua: A survey. Department of Entomology Report 432. Wageningen Agricultural University, The Netherlands.

Vorley W. T. (1992) Putting industry's IPM training and extension responsibility into practice in developing countries. In Papers presented by Ciba-Geigy. 19th Int. Cong. Entomol. Beijing.

Wasilewski A. (1987) The quiet epidemic, pesticide poisonings in Asia. IDRC Reports 16, 18-19.

Wittwer S. H. (1979) Pesticides as part of the food production system. In 9 th Int. Cong. Entomology 1, 222-224, Burgess Publishing Co., Washington. 